\title{
Foundation Investigations for the Bhaunrat Dam Project - A Case Study
}

\author{
Shahid Noor*, Rajaretnam Chitra, Manish Gupta, Amardeep Singh \\ Central Soil and Materials Research Station, Ministry of Water Resources, River Development and Ganga Rejuvenation, Government of \\ India, New Delhi, India
}

Email address:

shahidnoor19@gmail.com (S. Noor)

${ }^{*}$ Corresponding author

\section{To cite this article:}

Shahid Noor, Rajaretnam Chitra, Manish Gupta, Amardeep Singh. Foundation Investigations for the Bhaunrat Dam Project - A Case Study. American Journal of Civil Engineering. Vol. 6, No. 1, 2018, pp. 34-38. doi: 10.11648/j.ajce.20180601.16

Received: November 28, 2017; Accepted: December 18, 2017; Published: January 5, 2018

\begin{abstract}
The geotechnical investigations play an important role in economic viability and structural stability of a dam project. The geotechnical investigation for dam project involves the borrow area investigations and foundation investigations. The borrow area locations and characteristics decide the economic viability of earthen dam project. Borrow area investigations characterizes the construction material in the vicinity of dam site, depth of construction material, extent of construction material. The foundation investigation is carried out to evaluate the compactness for foundation and abutments for the dam project, treatment to be given to foundation and depth of excavation of foundation. The extent of foundation investigation depends upon the site conditions but it provide the information regarding type of the soil or rock strata in the foundation or abutment at dam site, depth of rock, water table and locations of buried channels, seams, joints and fissures etc. The foundation investigations decide the structural safety of a dam project. The present paper presents the foundation investigations carried out for construction of Bhaunrat Dam Project, Uttar Pradesh.
\end{abstract}

Keywords: Earthen Dam, Foundation Investigations, Trial Pits, Insitu Density, Shear, Consolidation

\section{Introduction}

\section{Bhaunrat Dam Project}

The Proposed Bhaunrat Dam Project, Uttar Pradesh is planned across the river Jamuni (Batwa Basin) in Mahrauni Tehsil of Lalitpur District in Uttar Pradesh with $2435^{\prime} 10^{\prime} \mathrm{N}$ latitude and $7840^{\prime} 00^{\prime \prime} \mathrm{E}$ longitudes. The main purpose of dam is to provide the irrigation facilities of 16,000 hectare in the drought prone area of Bundelkhand region of Uttar Pradesh. The project envisages the construction of $22 \mathrm{~m}$ high earthen dam on the river Jamuni with a gross storage capacity of $45.08 \mathrm{MCM}$. The total length of dam is $4.2 \mathrm{~km}$. The geotechnical investigations involves the foundation investigations to assess the compactness of the foundation. Figure 1 presents the index plan of the Bhaunrat Dam project, Uttar Pradesh.

\section{Geology of the Reservoir Area}

The dam site falls in Bundelkhand Province of Indian Peninsula. Bundelkhand Province is a triangular segment composed of rocks of Bundelkhand Granitoid Complex comprising granite-granodiorite, quartzo-feldspathic gneisses and enclaves of meta sedimentary and meta volcanic rocks, quartz reefs and dyke of dolerite. Beside the rock exposure of Bundelkhand Granitoid Complex (BGC), the dam area also comprises sediment of Band Older Alluvium and Newer Alluvium. The Band Older Alluvium lying over the BGC consists of red to deep brown sand with gravel lenses, silt and clay with kankar. The Newer Alluvium lies over the Banda Alluvium and further divided into Trace and Channel Alluvium. 


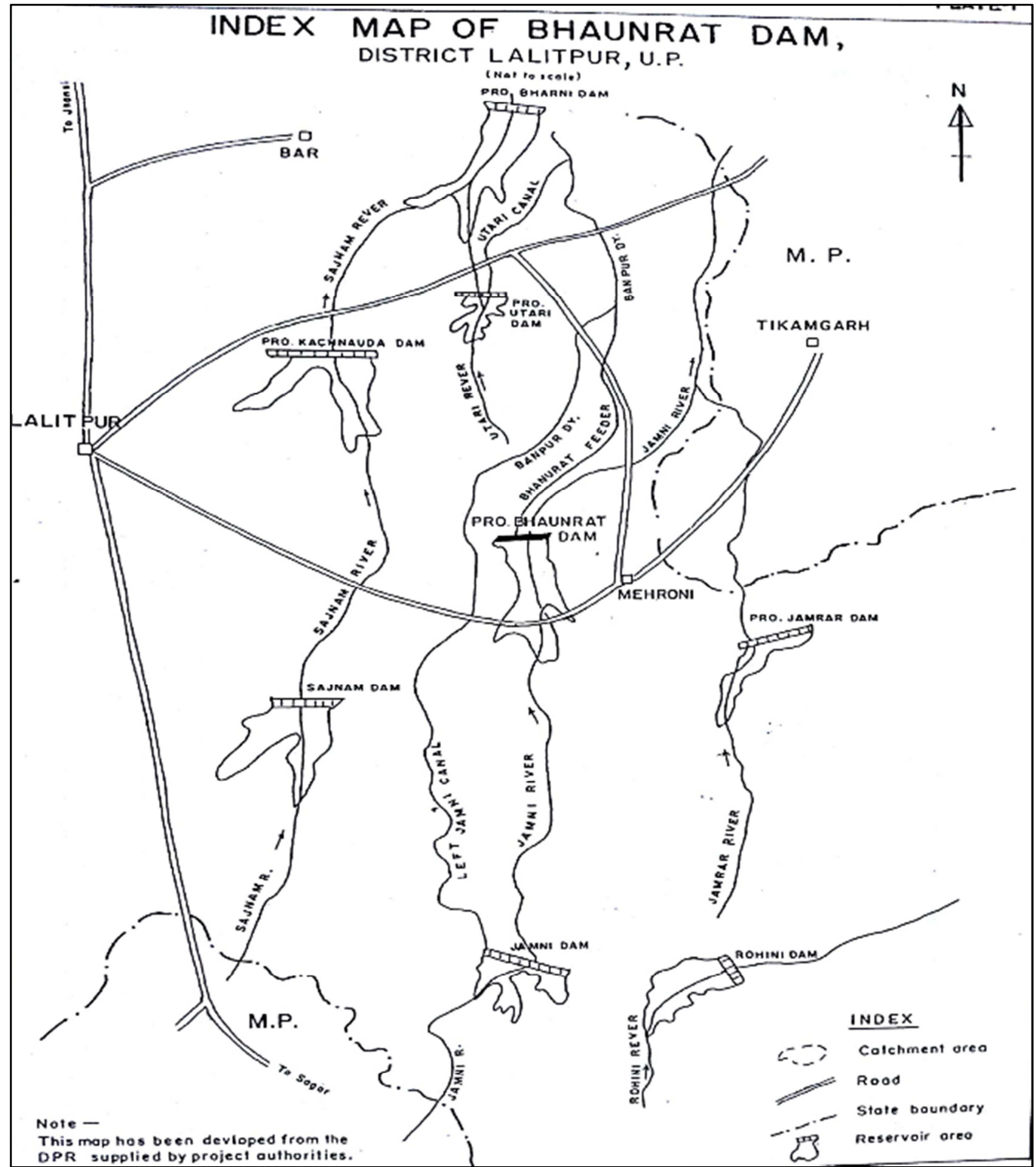

Figure 1. Index Plan of Bhaunrat Dam.

\section{Field Investigations}

Foundation investigations includes assessment the compactness of the foundation conditions along the dam axis. It was observed from the geological report that a total of 14 bore holes. were drilled along the dam axis and the bed rock level varies between $0.00 \mathrm{~m}$ to $9.00 \mathrm{~m}$ below ground level with an average depth of $3.50 \mathrm{~m}$. However the fresh rock level varies from $3.0 \mathrm{~m}$ to $17.6 \mathrm{~m}$. During the present geotechnical investigations for the foundation condition assessment, a total of 10 foundation pits were excavated, 5 each on the right bank and left bank and a total of 10 undisturbed soil samples were collected from the foundation pits for laboratory investigation on foundation material to assess the condition of foundation. The samples were collected from a depth of $0.35 \mathrm{~m}$ to $6.40 \mathrm{~m}$. The location of foundation trial pits (TP-1 to TP-10) along the dam axis is shown in Figure 2. And $\log$ of trial pits are presented in Figure 3.

\section{Laboratory Investigations}

\subsection{Mechanical Analysis and Atterberg Limits}

All the 10 undisturbed soil samples were subjected to Mechanical Analysis and Atterberg limits tests \{as per SP-36 (Part-1)-1978\}. The grain size analysis of the tested soil samples indicate that the tested soil samples in general possess predominantly silt sizes followed by the clay sizes and gravel sizes with few exceptions. The grain sizes of the tested soil samples indicate that the clay sizes vary from $2.4 \%$ to $21.5 \%$, silt sizes vary from $18.3 \%$ to $73.2 \%$, fine sand sizes vary from $1.9 \%$ to $22.7 \%$, medium sand sizes vary 
from $1.9 \%$ to $21.4 \%$, coarse sand sizes vary from $0.0 \%$ to $9.3 \%$ and the gravel sizes vary from $1.2 \%$ to $44.5 \%$. The plasticity index values of the tested soil samples indicate that all the tested soil samples in general possess low to medium plasticity characteristics.

Based on the results of grain size distribution and Atterberg limits tests, out of the 10 tested soil samples, 5 soil samples fall under CI (Clay with Medium Compressibility), 4 soil sample fall under CL (Clay with Low Compressibility) and the remaining one soil sample falls under GC (Clayey Gravel) group of Bureau of Indian Standard soil classification system (IS: 1498-1970). The graphical representations of grain size distribution of the tested soil samples are presented in Figure 4.

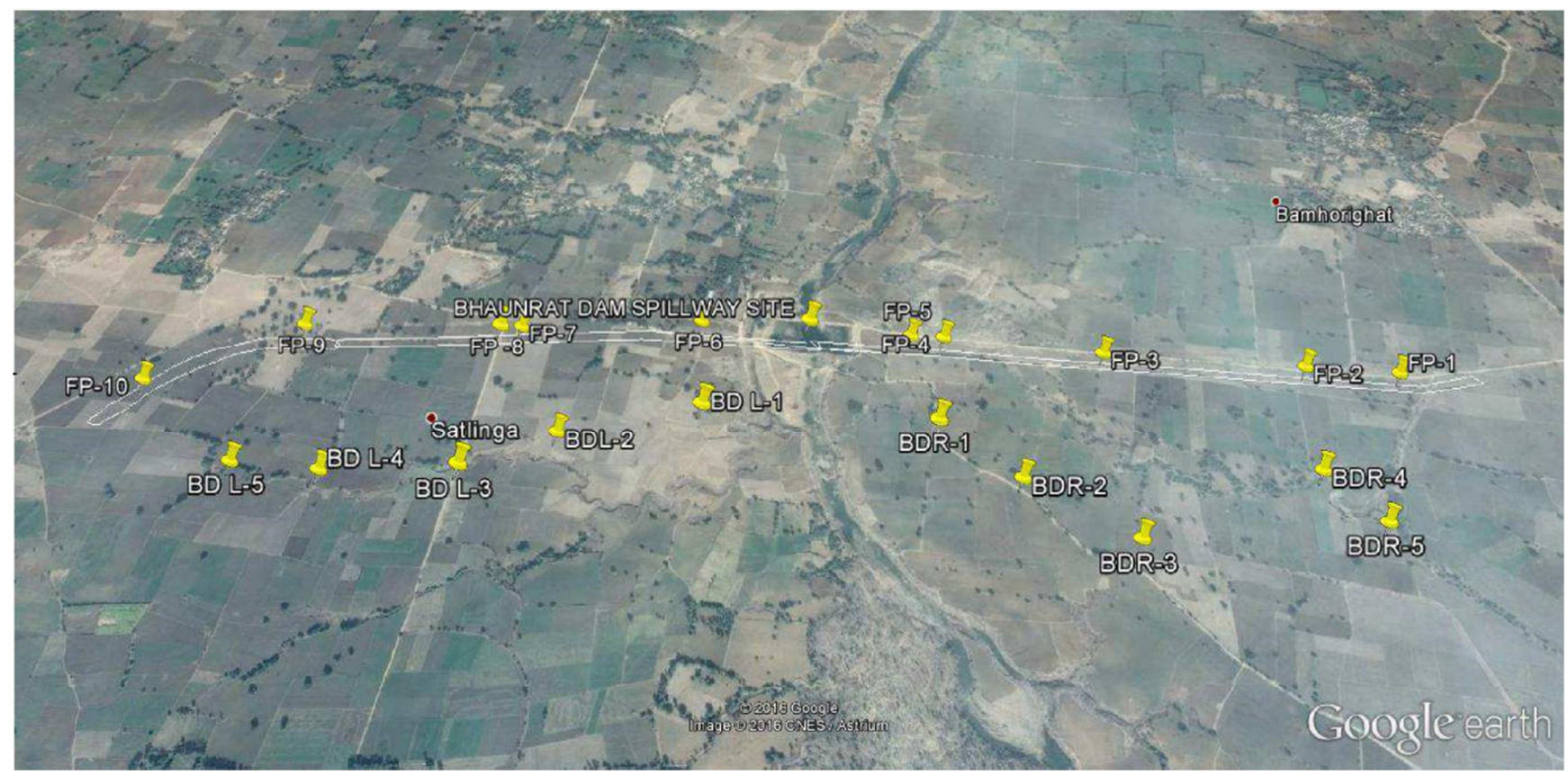

Figure 2. Location of Trial Pits along the Dam Axis.

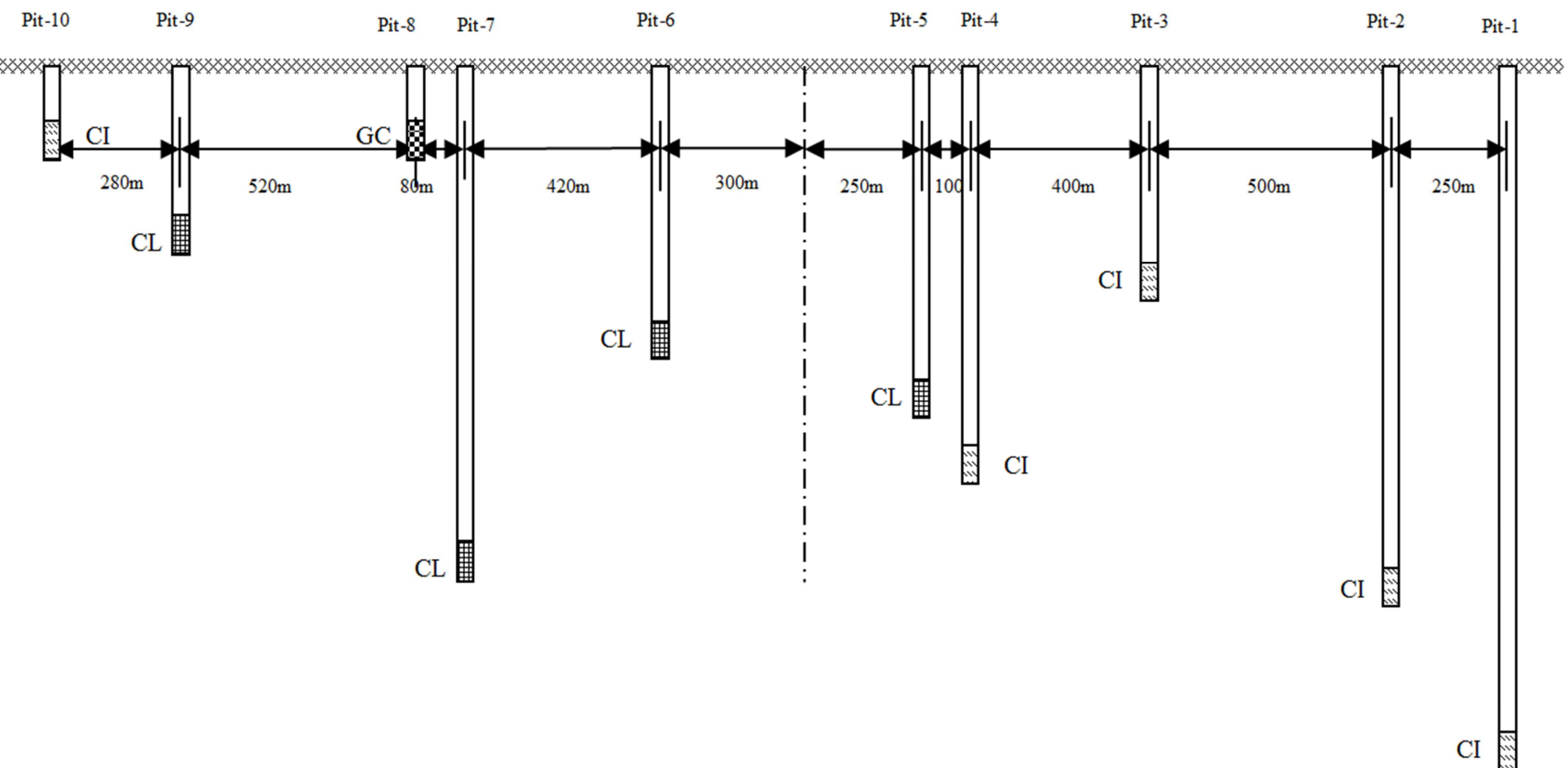

Figure 3. Profile of the ground along the dam Axis. 


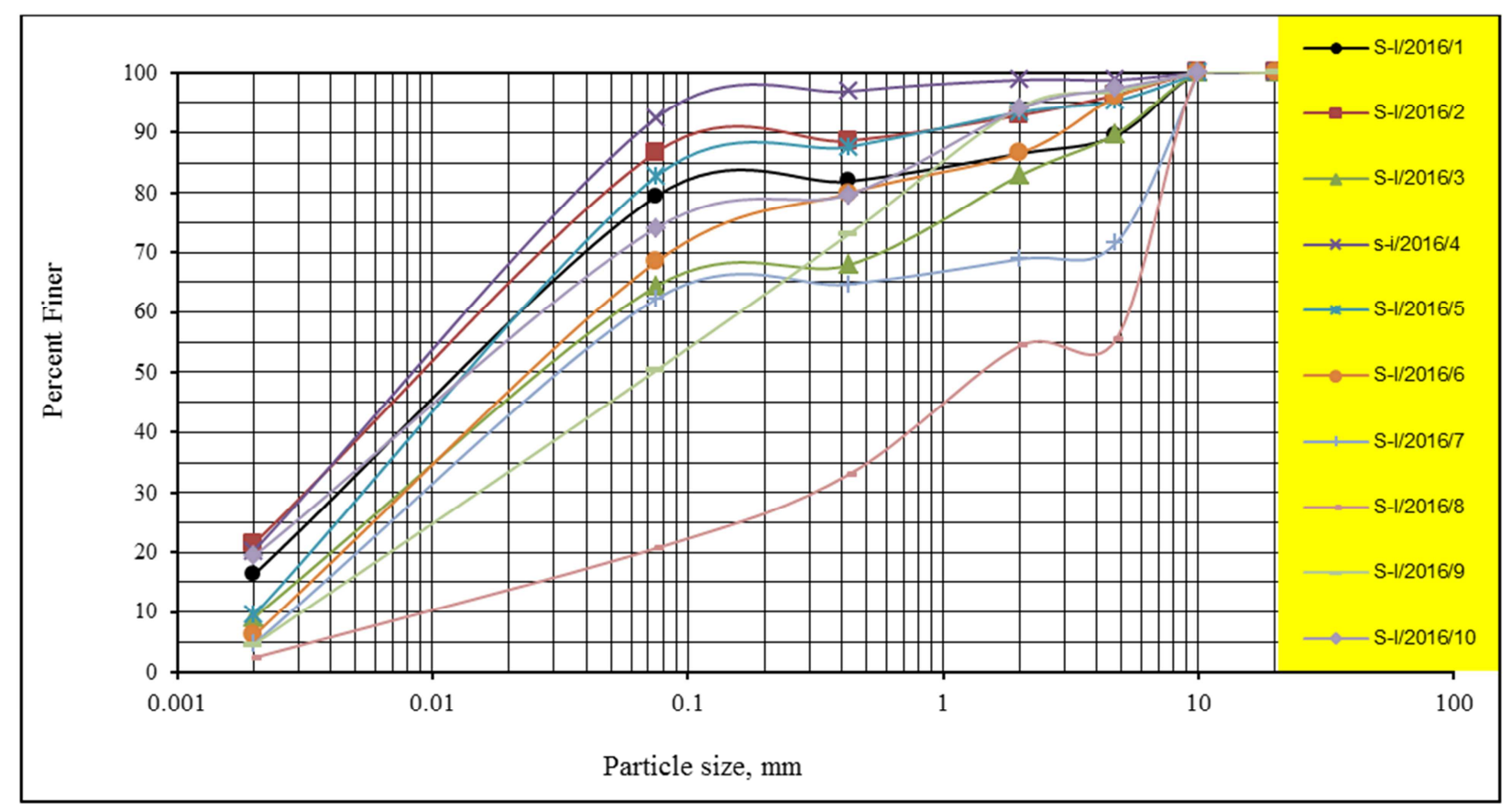

Figure 4. Grain Size Distribution Curve.

\subsection{Insitu Density and Natural Moisture Content}

Nine undisturbed soil samples collected from the foundation pits were subjected to Insitu Density and Natural Moisture Content tests. The values of Insitu Dry Density and Natural Moisture Content of the tested soil samples vary from $1.617 \mathrm{~g} / \mathrm{cc}$ to $1.718 \mathrm{~g} / \mathrm{cc}$ and $10.3 \%$ to $14.5 \%$ respectively and are presented in Table -1 .

\subsection{Specific Gravity}

All the 10 undisturbed soil samples were subjected to Specific Gravity test. The Specific Gravity values of the tested soil samples vary from 2.63 to 2.66 and are presented in Table -1 .

\subsection{Triaxial Shear}

Three selected undisturbed soil samples were subjected to Consolidated Undrained Triaxial Shear tests with pore water pressure measurement. The soil samples were consolidated and sheared under four different constant effective confining pressures of $1,2,3$ and $4 \mathrm{~kg} / \mathrm{cm}^{2}$ respectively after achieving full saturation by back pressure. The total shear strength parameters total cohesion (c) and total angle of shearing resistance $(\phi)$ of the tested soil samples vary from $0.27 \mathrm{~kg} / \mathrm{cm}^{2}$ to $0.33 \mathrm{~kg} / \mathrm{cm}^{2}$ and $12.4^{\circ}$ to $20.6^{\circ}$ respectively. The effective shear strength parameters effective cohesion $\left(\mathrm{c}^{\prime}\right)$ and effective angle of shearing resistance $\left(\phi^{\prime}\right)$ of the tested soil samples vary from $0.14 \mathrm{~kg} / \mathrm{cm}^{2}$ to $0.19 \mathrm{~kg} / \mathrm{cm}^{2}$ and $20.1^{\circ}$ to $29.0^{\circ}$ respectively. The results of Triaxial Shear tests - Consolidated Undrained with pore water pressure measurement of the tested soil samples are presented in Table -2 .

\subsection{One Dimensional Consolidation}

Four selected undisturbed soil samples were subjected to One Dimensional Consolidation test for ascertaining its consolidation and compressibility characteristics. The undisturbed soil samples were taken into the consolidation ring at the natural moisture and tested at different stress levels viz. $0.25,0.5,1.0,2.0,4.0$ and $8.0 \mathrm{~kg} / \mathrm{cm}^{2}$ respectively. The test results indicate that the tested soil samples exhibit low to medium compressibility characteristics. The consolidation test results are presented in Tables -3 to 5 .

Table 1. Insitu Density, Natural Moisture Content and Specific Gravity Test Results.

\begin{tabular}{lllll}
\hline \multirow{2}{*}{ Pit No. } & $\begin{array}{l}\text { Depth } \\
\text { (m) }\end{array}$ & \multicolumn{2}{l}{ Insitu Density/ Natural Moisture Content Test } \\
\cline { 2 - 5 } & Insitu Bulk Density g/cc & Insitu Dry Density g/cc & Natural Moisture content\% \\
\hline Pit 1 & $6.40-6.85$ & 1.854 & 1.674 & 10.7 \\
Pit 2 & $4.55-5.00$ & 1.812 & 1.641 & 10.4 \\
Pit 3 & $1.55-2.00$ & 1.912 & 1.718 & 11.3 \\
Pit 4 & $3.00-3.45$ & 1.904 & 1.663 & 14.5 \\
Pit 5 & $2.55-3.00$ & 1.925 & 1.709 & 12.6 \\
Pit 6 & $2.05-2.50$ & 1.917 & 1.695 & 13.1 \\
Pit 7 & $3.85-4.30$ & 1.890 & 1.713 & 10.3 \\
Pit 9 & $1.15-1.60$ & 1.811 & 1.617 & 2.65 \\
Pit 10 & $0.35-0.80$ & 1.872 & 1.641 & 2.6 \\
\hline
\end{tabular}


Table 2. Triaxial Shear Test Results.

\begin{tabular}{lllll}
\hline & \multicolumn{3}{l}{ Triaxial Shear Test } \\
\cline { 2 - 5 } Sample No. & \multicolumn{3}{l}{ Total shear parameter } & Effective shear parameter \\
\cline { 2 - 5 } & $\mathbf{c}$ & $\boldsymbol{\phi}$ & $\mathbf{c}^{\prime}$ & $\boldsymbol{\phi}^{\prime}$ \\
& $\mathbf{k g} / \mathbf{c m}^{2}$ & Degrees & $\mathbf{k g} / \mathbf{c m}^{2}$ & Degrees \\
\hline S-III/2016/2 & 0.33 & $12.4^{\circ}$ & 0.19 & $20.1^{\circ}$ \\
S-III/2016/4 & 0.31 & $15.3^{\circ}$ & 0.16 & $21.2^{\circ}$ \\
S-III/2016/6 & 0.27 & $20.6^{\circ}$ & 0.14 & $29.0^{\circ}$ \\
\hline
\end{tabular}

Table 3. Consolidation Test Results, $C_{v}$.

\begin{tabular}{llllll}
\hline & \multicolumn{6}{l}{ Coefficient of Consolidation, $\mathbf{C}_{\mathbf{v}} \times \mathbf{1 0}^{-4} \mathbf{c m}^{\mathbf{2}} / \mathbf{k g}$} \\
\cline { 2 - 6 } Sample No. & \multicolumn{6}{l}{ Stress level, $\mathbf{~ k g / \mathbf { c m } ^ { 2 }}$} & & & \\
\cline { 2 - 6 } & $\mathbf{0 . 2 5 - 0 . 5 0}$ & $\mathbf{0 . 5 0 - 1 . 0}$ & $\mathbf{1 . 0 - 2 . 0}$ & $\mathbf{2 . 0 - 4 . 0}$ & $\mathbf{4 . 0 - 8 . 0}$ \\
\hline S-III/2016/2 & 10.69 & 6.86 & 3.21 & 1.44 & 0.89 \\
S-III/2016/4 & 12.80 & 8.79 & 5.23 & 3.70 & 2.50 \\
S-III/2016/6 & 12.69 & 7.60 & 4.07 & 2.61 & 1.95 \\
S-III/2016/7 & 14.46 & 8.95 & 6.37 & 4.40 & 2.97 \\
\hline
\end{tabular}

\subsection{Chemical Analysis}

Three selected soil samples were subjected to chemical analysis with particular reference to $\mathrm{PH}, \mathrm{CaCO} 3$, Total Soluble Solids, Water Soluble Sulphates, Water Soluble Chloride and Organic Matter. The test results of chemical analysis indicate the normal behavior of soil.

Table 4. Consolidation Test Results, $m_{v}$.

\begin{tabular}{|c|c|c|c|c|c|}
\hline \multirow{3}{*}{ Sample No. } & \multicolumn{5}{|c|}{ Coefficient of Volume Compressibility, $\mathrm{m}_{\mathrm{v}} \times 10^{2} \mathrm{~cm}^{2} / \mathrm{kg}$} \\
\hline & \multicolumn{5}{|c|}{ Stress level, $\mathrm{kg} / \mathrm{cm}^{2}$} \\
\hline & $0.25-0.50$ & $0.50-1.0$ & $1.0-2.0$ & 2.0-4.0 & 4.0-8.0 \\
\hline $\mathrm{S}-\mathrm{III} / 2016 / 2$ & 5.23 & 4.89 & 4.18 & 3.08 & 2.08 \\
\hline S-III/2016/4 & 5.51 & 4.90 & 4.31 & 2.89 & 2.04 \\
\hline S-III/2016/6 & 6.78 & 5.17 & 3.83 & 2.31 & 1.57 \\
\hline S-III/2016/7 & 7.49 & 5.05 & 3.41 & 2.29 & 1.47 \\
\hline
\end{tabular}

Table 5. Consolidation Test Results, $C_{c} \& C_{s}$.

\begin{tabular}{lll}
\hline Sample No. & Compression Index, $\mathbf{C}_{\boldsymbol{c}}$ & Swelling Index, $\mathbf{C}_{\mathbf{s}}$ \\
\hline $\mathrm{S}-\mathrm{III} / 2016 / 2$ & 0.2152 & 0.0264 \\
$\mathrm{~S}-\mathrm{III} / 2016 / 4$ & 0.2230 & 0.0276 \\
$\mathrm{~S}-\mathrm{III} / 2016 / 6$ & 0.1892 & 0.0198 \\
$\mathrm{~S}-\mathrm{III} / 2016 / 7$ & 0.1619 & 0.0185 \\
\hline
\end{tabular}

\section{Conclusions}

Based on the findings of the foundation investigations carried out for the Proposed Bhaunrat Dam Project, Uttar Pradesh, the following conclusions have been arrived at:

The grain size analysis of the tested soil samples indicate that the tested soil samples possess predominantly silt sizes followed by the clay sizes and gravel sizes with few exceptions. The plasticity index values of the tested soil samples indicate that all the soil samples in general possess low to medium plasticity characteristics.

Based on the results of grain size distribution and Atterberg's limits tests, out of the 10 tested soil samples, 5 soil samples fall under CI (Clay with Medium Compressibility), 4 soil sample fall under CL (Clay with Low Compressibility) and the remaining 1 soil sample falls under GC (Clayey Gravel) group of Bureau of Indian Standard soil classification system. The values of Insitu Dry Density and
Natural Moisture Content of the tested soil samples vary from $1.617 \mathrm{~g} / \mathrm{cc}$ to $1.718 \mathrm{~g} / \mathrm{cc}$ and $10.3 \%$ to $14.5 \%$ respectively. Based on the Insitu Density test, it is inferred that the foundation strata possess good compactness.

The total shear strength parameters total cohesion (c) and total angle of shearing resistance $(\phi)$ of the tested soil samples vary from $0.27 \mathrm{~kg} / \mathrm{cm} 2$ to $0.33 \mathrm{~kg} / \mathrm{cm} 2$ and $12.4^{\circ}$ to $20.6^{\circ}$ respectively. The effective shear strength parameters effective cohesion $\left(c^{\prime}\right)$ and effective angle of shearing resistance $\left(\phi^{\prime}\right)$ of the tested soil samples vary from $0.14 \mathrm{~kg} / \mathrm{cm} 2$ to $0.19 \mathrm{~kg} / \mathrm{cm} 2$ and $20.1^{\circ}$ to $29.0^{\circ}$ respectively. Based on the results of Triaxial Shear tests conducted on the soil samples, it is inferred that the tested soil samples are likely to exhibit good shear strength characteristics. Based on the one dimensional consolidation test conducted on the soil samples, it is inferred that borrow area materials are likely to undergo low to medium compressibility depending upon the imposed loads.

\section{Disclaimer}

The views expressed in this paper are strictly individual views of the authors and do not, in any way, represent the views of the department/organization where they are presently working.

\section{References}

[1] Alam Singh, (1981), "Soil Engineering in Theory and Practice (Vol. 1)”, Asia Publishing House, Bombay.

[2] B. M. Das (1994), “Principles of Soil Engineering” third Edition, PWS Publishers, Boston.

[3] CSMRS Report (2016). "Report on the Foundation Investigations for the Proposed Bhaunrat Dam Project, Uttar Pradesh", Report No. 02/Soil-III/SM/CSMRS/E/12/2016, December 2016.

[4] CSMRS Report (2016). "Report On Laboratory Investigations On Soil Samples Collected From The Borrow Areas For The Proposed Bhaunrat Dam Project, Uttar Pradesh", Report No. 01/Soil-III/SM/CSMRS/E/12/2016, December 2016.

[5] Geological Survey of India report on "Geotechnical Investigations for the Bhaunrat Dam Project, District Lalitpur, Uttar Pradesh".

[6] EM 1110-2-2300, (1982), Earth manual, Publication of United States Bureau of Reclamation.

[7] Fell, R., Macgregor, P., \& Stapledon, D. (1992), Geotechnical Engineering of Embankment dams.

[8] IS: 12169-1987: Criteria for Design of Small Embankments Dams.

[9] IS 1498-1970: Classification and Identifications of Soils for General Enginee [ring Purposes].

[10] SP-36 (Part-1)-1978: Standard Publication on Soil Testing in laboratory, Bureau of Indian Standards. 